\title{
African traditional medicine struggles to find its place within health care
}

I was to have been the "Decade of African Traditional Medicine," a curious, hybrid mix of herbalism and spirituality, in which disease is perceived to be a function of imbalance between a person and his social environment or spiritual state, i.e., a person's guilt or sin, or even the direct retribution of a god. Treatment, in turn, ranges from incantations to fasting and bleedings but is most often an herbal concoction imbued with metaphysical significance.

The African Union Summit of Heads of State and Government vowed in 2001 that the forthcoming decade would incorporate the practice of African traditional medicine into their health care systems by increasing institutional capacity and developing national regulatory frameworks.

The progress to date?

Checkerboard, at

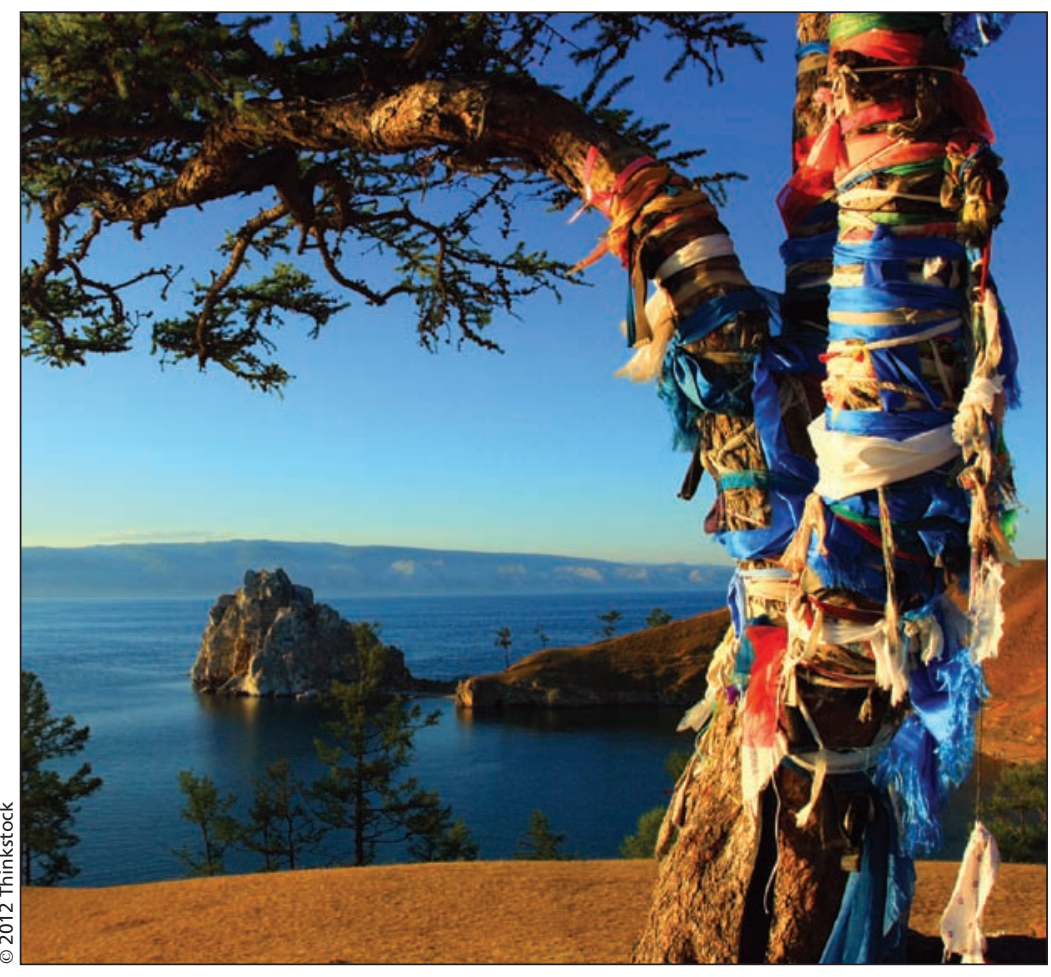

Traditional African medicine is a curious, hybrid mix of herbalism and spirituality. ditional medicine practitioners were established."

But major impediments remain, the progress report added, including “(i) limited financial and human resources; (ii) weak regulatory capacity which has
African traditional medicine, he says. "From [a] scientific point of view, aspects of African traditional medicine that cannot be proven by science such as spiritism, psychic healing, soothsaying, and fortune telling — are not part of the training of the medical herbalists, and thus are not part of the integration."

Annan's department has trained 112 medical herbalists since 2001, some 30 of whom are working in public hospitals. Some of those have been and will be involved in a pilot project established in 2010 by the nation's Ministry of Health that designated 18 public hospitals for integration of some of the herbal components of African traditional medicine into their daily practice.

Despite some initial skepticism about the role of herbalists, there has been some progress, says Ama Kyeraa Amoh-Barimah, head best, according to a World Health Organization progress report on the commitment (www.afro .who.int/en/downloads/doc_download /6665-afrrc61 pr2-progress-report-on -decade-of-traditional-medicine-in-the -african-region.html). "The number of countries with national traditional medicine policies increased from eight in 1999/2000 to 39 in 2010 and those with national traditional medicine strategic plans rose from zero to 18. Country regulatory frameworks increased in number from 1 in 1999/2000 to 28 in 2010. Within these frameworks various instruments such as the code of ethics and the legal framework for tra- led to malpractices in traditional medicine in some countries; (iii) insufficient scientific data on the safety, efficacy and quality of traditional medicines; and (iv) unfavorable policy, economic and regulatory environments for local production of traditional medicines."

The lack of scientific validity has definitely been an impediment, says Dr. Kofi Annan, head of the Department of Herbal Medicine at Kwame Nkrumah University of Science and Technology in Kumasi, Ghana.

As a consequence, in Ghana, efforts at integration have been confined primarily to some of the herbal aspects of of the herbal medicine unit at the Cape Coast Metropolitan Hospital. "We even have internal referral systems so that when physicians identify patients who need alternative forms of treatment for diseases such as hypertension and diabetes, they refer them to us and we also refer cases that need orthodox treatments to physicians."

Amoh-Barimah says that among the herbal remedies that have most readily been incorporated into the hospital's offered treatments is a mixture of herbs that has Cryptolepis sanguinolenta (a root traditionally used as an antimalarial) as an active ingredient 
and is used to treat hypertension. Others include "asena decoction," which is derived in part from Kigelia africana and used to treat arthritis; a powdered extract of the plant Bridelia ferruginea that is used to treat diabetes; a mixture called "ulcerplex oral" that is derived from Tetrapleura tetraptera and used to manage peptic ulcer; a "diagellates elixir" made from the plant Psidium guajava that is used to manage intestinal worms, peptic ulcer, and dyspepsia; as well as a mixture called "campa T" that is derived from Thonningia sanguinea and used to manage asthma and waist pain.

The government of Ghana has approved a list of 86 herbal remedies for use in hospitals (www.tm-moh.gov.gh /v2/images/stories/RECOMMENDED _HERBAL_DRUG_LIST.pdf), says
Peter Arhin, director of the Traditional and Alternative Medicine Directorate of the Ministry of Health.

But most are not popular among patients as they are liquid preparations and are often thought to be inconvenient, Arhin says. "We are looking for support to build pharmaceutical infrastructure to enable us [to] prepare herbal medicines in convenient dosage forms like tablets and capsules and to also help us conduct more observational studies on the efficacy and safety of the medicines."

Many people prefer tablets and capsules to liquid herbal medicines, explains Nana Yaa Agyeman, executive director of Sharecare Ghana, a patient advocacy organization. "I don't trust the quality of the water used for preparing liquid herbal medicines but for tablets and capsules, I don't have such fears."

In the long-term, integration of African traditional medicine with Western medicine will require a more scientific approach and more scientific training of herbalists, says Dr. Kofi Busia, traditional medicine officer at the West African Health Organisation, based in Bobo-Dioulasso, Burkina Faso.

To that end, the organization has been funding workshops for training traditional practitioners and has piloted software designed to facilitate access to the services of traditional African medicine practitioners "because they are integral to primary health care in Africa," Busia says. - Bernard Appiah, College Station, Tex.

CMAJ 2012. DOI:10.1503/cmaj.109-4277 